\title{
Impact of frozen storage time on the volatile profile of wheat bread crumb
}

\author{
$\underline{\text { Joana Pico }}^{\mathrm{a}^{*}}$, Mario M. Martínez ${ }^{\mathrm{b}, \mathrm{c}}$, José Bernal $^{\mathrm{a}}$, Manuel Gómez ${ }^{\mathrm{c}}$
}

${ }^{a}$ I.U.Cinquima, Analytical Chemistry Group, University of Valladolid, Paseo de Belén Street 7, E-47011 Valladolid, Spain.

${ }^{b}$ Present address: Whistler Center for Carbohydrate Research, Department of Food Science, Purdue University, 745 Agricultural Mall Drive, West Lafayette, IN 47906, USA.

${ }^{\mathrm{c}}$ Food Technology Area, E.T.S. Ingenierías Agrarias, University of Valladolid, Madrid Avenue 57, E- 34071 Palencia, Spain.

*Corresponding author: Joana Pico

e-mail: joana.pico@uva.es

\section{Abstract}

The freezing of wheat bread before aroma analyses is a common practice in order to preserve loss of the volatile profile. However, the impact of the frozen storage time on the aroma profile has not been studied. For this purpose, the volatile profiles of wheat bread frozen for 1, 2 and 4 weeks were analysed employing solvent extraction and static headspace methoologies with GC/MS. The results revealed that the freezing was effective to prevent the loss of volatiles during the first week. However, after two weeks, there was an increase of volatile compounds, probably generated by chemical reactions. Thus, a maximum of one week of frozen storage was recommended when using the solvent extraction methodology. When using the static headspace method, the samples should be analysed on the same day as preparation, since the extraction was surprisingly increased due to the starch retrogradation that occurred during freezing. Key words: wheat bread aroma; frozen storage time; solvent extraction; SHS-GC/MS; starch retrogradation.

\footnotetext{
Abbreviations: Anova (analysis of variance); FU (farinograph units); GC/MS (gas chromatography-mass spectrometry); RH (relative humidity); SHS (static headspace); SIM (selected ion monitoring).
} 


\section{Introduction}

The aroma of bread is one of the main characteristics perceived by consumers. The more attractive the aroma is, the more likely the bread will be consumed. Thus, the development of new recipes that improve the bread aroma as well as the quality control of the bread aroma itself are key factors to ensure consumer acceptability. Therefore, accurate analytical methods are essential to measure the aroma of bread. In this context, the freezing of wheat bread samples, in order to preserve the volatile compounds, is usually required prior to chemical analyses due to logistic questions of shipping or production on a different day than the analyses. Numerous studies reported the "freezing of the bread sample until the aroma analysis" without checking if the volatile profile even changed at freezing temperatures (Bianchi, Careri, Chiavaro, Musci, \& Vittadini, 2008; Luning, Roozen, Moëst, \& Posthumus, 1991; Paraskevopoulou, Chrysanthou, \& Koutidou, 2012). Thus, it is decisive to ensure that the content of volatile compounds remains almost unchanged during freezing to achieve reliable results in aroma research. The present literature concerning the evolution of the volatile compounds during storage has been focused on the changes of the aroma profile at room temperature (Chiavaro, Vittadini, Musci, Bianchi, \& Curti, 2008; Jensen, Oestdal, Skibsted, Larsen, \& Thybo, 2011a; Jensen, Oestdal, Skibsted, \& Thybo, 2011b; Latou, Mexis, Badeka, \& Kontominas, 2010; Plessas et al., 2008, 2011). The extension of shelf-life is one of the biggest challenges for the baking industry today, since the short shelf-life of bread has caused considerable economic losses annually (Plessas et al., 2011). However, as to our knowledge, there is no literature concerning the evolution of volatile compounds during freezing.

Therefore, the aim of the present study was to investigate the frozen storage time suitable to preserve the volatile profile of wheat bread samples, in order to achieve reliable aroma analyses. For this purpose, bread samples frozen for one, two and four 
weeks were analysed using a static headspace methodology for the very volatile compounds and a solvent extraction methodology for the rest of common volatile compounds studied in wheat bread, both with GC/MS.

\section{Materials and methods}

\subsection{Materials}

Strong wheat flour $(11.73 \%$ and $11.20 \% \mathrm{w} / \mathrm{w}$ of moisture and protein contents, respectively) from Harinera Castellana (Medina del Campo, Valladolid, Spain), ascorbic acid from Sigma Aldrich (Gillingham, UK), Saccharomyces cerevisiae (Saf-instant yeast) from Lesaffre (Lille, France), salt from Ybarra (Sevilla, Spain) as well as tap water were used to make the bread samples. To check the retention time and the mass spectra of the main volatile compounds, the 38 analytical standards listed in Table S1 were purchased from Sigma Aldrich (Gillingham, UK).

\subsection{Methods}

\subsubsection{Bread making and storage conditions}

The following ingredients, as $\%$ on wheat flour basis, were utilized: salt (1.8\%), instant yeast $(1 \%)$, ascorbic acid $(0.01 \%)$ and water $(52.7 \%$, calculated to obtain 500 Farinograph Units, FU). The dough was made with $1500 \mathrm{~g}( \pm 0.05 \mathrm{~g})$ of flour and the amount of water was adjusted to an average moisture content of $12 \%$. The ingredients were mixed using a Kitchen-Aid Professional mixer (KPM5, KitchenAid, St. Joseph, Michigan, USA) for $15 \mathrm{~min}$ at speed 2. Six pieces of dough of $500 \mathrm{~g}$ each were rounded and left for fermentation for $90 \mathrm{~min}$ in a chamber at $30^{\circ} \mathrm{C}$ with $75 \% \mathrm{RH}$. Later, the pieces of fermented dough were baked at $180^{\circ} \mathrm{C}$ for $40 \mathrm{~min}$ and left for $30 \mathrm{~min}$ to reach room temperature. One piece of bread was analysed as freshly prepared sample (day 0), as a baseline for comparison over time. First, the fresh bread was cut into slices of $5 \mathrm{~cm}$ long and then the crumb was separated $1 \mathrm{~cm}$ from the crust, to avoid contamination of 
the crumb with crust volatile compounds. Then, the crumb was frozen with liquid nitrogen and ground in an Ika grinder model M20 (Staufen, Germany) for 10 seconds. Finally, $50 \mathrm{~g}$ of the powder was submitted to volatile compounds analyses (sub-section 2.2.2). The crumb of another piece of bread was separated from the crust in the same way, ground and frozen with liquid nitrogen, as was reported by studies that freeze the crumb separated from the crust until their analysis (Paraskevopoulou et al., 2012; Bianchi et al., 2008). The crumb powder was separated into three aluminum packets placed in polyethylene bags and frozen at $-21^{\circ} \mathrm{C}$ for one, two and four weeks, respectively, until their volatile compounds were analysed. Finally, another piece of bread was taken as a control sample of the evolution of the volatile compounds over time at room temperature, in order to compare the changes during freezing with conventional room storage. It was stored in a laboratory oven, wrapped in aluminum foil, at a controlled temperature of $22^{\circ} \mathrm{C}$. This bread was stored with the crust in order to protect the volatile compounds from dramatic losses that could prevent the analysis of changes due to the natural aging of bread. After one week, the crumb was separated from the crust, frozen with liquid nitrogen and grinded and finally submitted to volatile compounds analyses (as was explained for the fresh bread). Experiments were made with a piece of bread stored for two weeks at room temperature, but the volatile compounds analysis was not accomplished because the bread was completely stale. All the samples were thawed for $30 \mathrm{~min}$ before the aroma analyses were conducted. The whole experiment was conducted in duplicate $(n=2)$.

\subsubsection{Volatile compounds analyses: Solvent extraction, Static Headspace \& GC/MS}

The fresh sample, the control sample (stored one week at room temperature) as well as the three frozen samples (one, two and four weeks) were analysed following the solvent extraction methodology for the analysis of volatile compounds in wheat bread crumb developed by our research group (Pico, Nozal, Gómez \& Bernal, 2016). This is 
considered a suitable method to examine the possible changes in the volatile compounds of frozen crumb since the reported limits of detection have been lower than $35 \mu \mathrm{g} \mathrm{Kg}^{-1}$. Each sample was analysed in duplicate $(n=2)$.In order to evaluate the changes of the very volatile compounds, static headspace analyses of ethyl acetate and ethyl alcohol were performed, which eluted with the solvent in the lipases method. Thus, $1 \mathrm{~g}( \pm 0.050$ g) of each sample was placed in a $20 \mathrm{~mL}$ vial and sealed with a septum cap. The samples were then extracted for $90 \mathrm{~min}$ at $90^{\circ} \mathrm{C}$, without agitation, in a Static Headspace autosampler 7694 from Hewlett Packard (Palo Alto, California, USA). The loop and transfer line temperatures were $100^{\circ} \mathrm{C}$ and $105^{\circ} \mathrm{C}$, respectively. The carrier gas employed was helium, supplied by Carburos Metálicos (Barcelona, Spain), with a carrier gas pressure of 23 psi. The vial pressurization was 14 psi for $0.2 \mathrm{~min}$. The loop filling time was $0.2 \mathrm{~min}$, the equilibration loop time was $0.05 \mathrm{~min}$ and the injection time was $1 \mathrm{~min}$. Each sample was analysed in duplicate $(\mathrm{n}=2)$. GC-MS conditions for the solvent extraction methodology are the same that those previously described (Pico, Nozal, Gómez \& Bernal, 2016). Specifying the gradient conditions, for the solvent extraction methodology the temperature ranged from $45^{\circ} \mathrm{C}(1.5 \mathrm{~min})$ to $100^{\circ} \mathrm{C}(0 \mathrm{~min})$ at $7^{\circ} \mathrm{C} / \mathrm{min}$, after which the temperature was increased to $114^{\circ} \mathrm{C}(3 \mathrm{~min})$ at $6^{\circ} \mathrm{C} / \mathrm{min}$, and then to $136^{\circ} \mathrm{C}(0 \mathrm{~min})$ at $1.5^{\circ} \mathrm{C} / \mathrm{min}$. Finally, the temperature was raised to $245^{\circ} \mathrm{C}$ at $85^{\circ} \mathrm{C} / \mathrm{min}$. This temperature was held for $25 \mathrm{~min}$ in order to elute the hydrolysed fat (glycerol and free fatty acids). For static headspace (SHS) analyses, the temperature ranged from $45^{\circ} \mathrm{C}(1.5 \mathrm{~min})$ to $100^{\circ} \mathrm{C}(0 \mathrm{~min})$ at $7^{\circ} \mathrm{C} / \mathrm{min}$, and afterwards the temperature was increased to $114^{\circ} \mathrm{C}(6.7 \mathrm{~min})$ at $1{ }^{\circ} \mathrm{C} / \mathrm{min}$. Analyses were performed in Selected Ion Monitoring (SIM) mode and the 38 volatile compounds were identified and confirmed by comparison of their retention times and mass spectra (target and qualifier ions) with standards (Table S1) and with the Mass Spectra Library (Wiley 7N edition). 


\subsubsection{Data analysis.}

The One-way Analysis of Variance (ANOVA) of the peak areas $(n=4$, each bread prepared in duplicate and analysed in duplicate) was computed by the software Statgraphics Centurion version XVII (Statpoint Technologies, Warrenton, Virginia) with statistical significance set at $p<0.05$.

\section{Results and discussion}

\subsection{Evolution of the volatile compounds during storage at room temperature}

A total of 38 volatile compounds reported as main volatile compounds in fresh wheat bread (Birch, Petersen, \& Hansen, 2014; Chiavaro et al., 2008; Jensen et al., 2011a; Latou et al., 2010; Makhoul et al., 2015; Plessas et al., 2008., 2011) were selected to examine the evolution during room temperature and frozen storages (Table S1). The results of the 38 selected volatile compounds for the fresh sample and the control sample stored one week are summarised in Table 1. Nearly all of the volatile compounds, disregarding the boiling point, polarity or functional group, decreased after one week of storage at room temperature. Only for 2,3-butanedione, 1-pentanol and 1,3butanediol there were no significant differences between the fresh sample and the stored sample, although they were present in low amount. This general tendency of volatile compounds to decrease after a few days of storage at room temperature has been commonly reported (Chiavaro et al., 2008; Jensen et al., 2011b; Plessas et al., 2011). These changes have been attributed to evaporation, staling of bread or oxidation reactions, although they have not been explained. Chiavaro et al. (2008) found in their study that the volatile compounds in the wheat bread crumb decreased between 1.5 and 3 times after 8 days of storage at $25^{\circ} \mathrm{C}$, which is in concordance with the average decrease of 2.75 times (39\% of losses) of our study. Ethyl acetate as well as ethyl alcohol also showed large decreases of 65 and 70\%, respectively, which can mainly be 
explained by their low boiling points. This decrease in the concentration of ethyl alcohol has been also reported by Plessas et al. (2008, 2011). However, there are some controversies with ethanol, since Latou et al. (2010) reported an increase after four days in the concentration of ethanol, although no explanation was given for this outcome. Acetoin was the only volatile compound that showed significant differences with an increase in the peak area after one week of storage at room temperature, which is in concordance with the work of Jensen et al. (2011a). Acetoin is mainly formed from the glycolysis of pyruvic acid in fermentation (Martínez-Anaya, 1996) by the yeast (Capozzi et al., 2016) and it can also be generated by Maillard reactions during baking (Poinot et al., 2010). However, Maillard processes typically do not occur during storage as a consequence of the moderate temperatures. Nevertheless, Birch, Petersen, \& Hansen (2013) reported that acetoin can be formed from the decarboxylation of 2acetolactate, which could tentatively proceed at room temperature. 2-ethyl-1-hexanol, 2methyl-1-propanol and 5-methyl-2-furaldehyde presented losses of around 90\% in the peak area of the fresh bread, which was surprising for 2-ethyl-1-hexanol and 5-methyl2-furaldehyde regarding their high boiling points. 2-methyl-1-butanol and 3-methyl-1butanol also presented high losses, around 60\%. Coincidentally, those were five of the seven volatile compounds that contained a methyl/ethyl radical group that could lead to some form of steric hindrance, making the interaction difficult between the volatile compounds molecules and the bread matrix. The interactions between the volatile compounds and starch have been attributed mainly to the amorphous fraction of starch, the amylose fraction (Arvisenet, Le Bail, Voilley, \& Cayot, 2002). This interaction is based on the generation of complexes, the volatile compound being the ligand that induces the formation of amylose single helices, normally of six glucoses per turn (Rappenecker \& Zugenmaier, 1981). As a consequence, the methyl/ethyl radical of 2ethyl-1-hexanol, 2-methyl-1-propanol, 5-methyl-2-furaldehyde, 2-methyl-1-butanol and 
3-methyl-1-butanol could have the potential to lead to high steric hindrances that complicated their access to the amylose helix and made the interaction difficult between the hydroxyl groups of the volatile compound and the amylose of starch. Although 3methylbutanoic acid and 2-methylbutanoic acid also contained the methyl radical, the high polarity of the acidic group could have the ability of retaining them in the crumb matrix via linkages to the starch by hydrogen bonds (Le Bail, Biais, Pozo-Bayón, \& Cayot, 2004). In the case of 1-propanol, the low boiling point justified a loss of $56 \%$. However, the losses higher than $50 \%$ of $\mathrm{R}-(+)$-limonene, furfural, ethyl octanoate, phenylacetaldehyde and 2,4-(E,E)-decadienal could be explained by a combination of steric hindrance together with a low polarity that could force the volatile compounds to be easily released from the matrix. The other 25 volatile compounds presented losses lower than $25 \%$ that were perfectly explained by the storage time.

\subsection{Changes in the volatile profile during frozen storage}

\subsubsection{Evolution of the volatile compounds over the four weeks of freezing}

The results of the 38 selected volatile compounds for the samples frozen for one, two and four weeks are provided in Table 2. Only 1-propanol and 4-vinylguaiacol showed no significant differences, as they remained almost constant during the freezing experiment. Regarding the first week of freezing, overall there was a decrease in concentration of the volatile compounds, with an average loss of $32 \%$ for the volatile compounds using the solvent extraction methodology and $21 \%$ and $19 \%$ for ethyl acetate and ethyl alcohol, respectively. Nevertheless, in comparison to the control sample, the freezing achieved an average preservation of $34 \%$ after one week. Furthermore, delving into more detail, in the sample stored at room temperature, 2methyl-1-propanol, 1-propanol, 3-methyl-1-butanol, ethyl alcohol, 2-methyl-1-butanol, ethyl acetate and hexanal experienced losses that were $79 \%, 56 \%, 54 \%, 51 \%, 50 \%$, $44 \%$ and $17 \%$ higher, respectively, than the frozen sample after one week. This finding 
could be attributed to their high volatility. Furfural and 2,4-(E,E)-decadienal also showed losses that were $25 \%$ and $73 \%$ higher in the room temperature sample than in the frozen one, but they do not present low boiling points. 2,3-butanedione was the only volatile compound that was better preserved at room temperature than during freezing, which was very surprising taking into account that 2,3-butanedione presents the lowest boiling point of the studied volatile compounds. Nonetheless, 2,3-butanedione can be generated from the oxidative decarboxylation of 2-acetolactate (Birch et al., 2013), a reaction that hypothetically is more spontaneous at room temperature. Alternatively, acetoin showed the same behaviour during freezing as at room temperature and increased after one week of storage but in a lesser degree. This can also be theoretically attributed to the possible deceleration of the decarboxylation of 2-acetolactate upon freezing. For the other 27 volatile compounds there were slight differences between storage at room temperature and freezing, with the differences lower than $15 \%$ attributable to the fluctuations of the GC/MS instrument in the measurement between different days (interday repeatability). Thus, the crust of the control sample seemed to act as an efficient protector of these 27 volatile compounds that differed minimally from the frozen samples.

As depicted in Figure 1, the total content of alcohols, acids and ketones followed the same general tendency during freezing, with a decrease in the total area during the first week, an increase during the second week and a final decrease leading up to the fourth week. Regarding the SHS-GC/MS analyses (Table 2), ethyl acetate also showed a decrease during the first week but then a constant increase leading up to the fourth week. For ethanol, there also was a decrease in the first week but a great increase in the second week (much higher than the fresh sample) and a slight decrease leading up to the fourth week. This indicates that the key differences between the evolutions of the 
volatile compounds during freezing were achieved during the second week. 2-methyl-1propanol, 2,3-butanediol, ethanol, 3-penten-2-ol, 2-methyl-1-butanol, benzyl alcohol, phenylethyl alcohol, ethyl acetate, acetoin as well as isobutyric acid, butyric acid, 3methylbutanoic acid and 2-methylbutanoic acid, were compounds that clearly increased from the first to the second week of freezing. Conversely, 3-methyl-1-butanol, 2octanone, 1-hexanol, 1-octen-3-ol, hexanoic acid and 2,4-(E,E)-decadienal remained almost constant during the second week of freezing. The other 17 volatile compounds experienced the expected decrease during the second week. These behaviours of increasing, decreasing or staying constant over the storage time instead of only decreasing, have been also reported by Jensen et al. (2011a), although at room temperature and over three weeks. Considering the outcomes during the first and second weeks from Jensen et al. (2011a), the alcohols showed exactly the same behaviour as in our case, with a decrease in the first week and an increase in the second week up to the initial value of the fresh sample. Although they reported that the content of alcohols did not change significantly, we found significant differences. Regarding the acids, they reported an increase during the first week and a decrease during the second week, while our results showed an increase during the second week and then a decrease again leading up to the fourth week. They explained the increase through the oxidation of the aldehydes, a reaction that tentatively could be susceptible to be delayed as a consequence of the freezing in our study. Furthermore, in our study the peak area of aldehydes decreased over four weeks, which could be justified by their intermediate state of oxidation, along with the possibility of their reduction to alcohols or oxidation to acids. For Jensen et al. (2011a) the aldehydes increased in the first two weeks explained by lipid oxidation, which on one hand was encouraged by the room temperature and, on the other hand, by the addition of soy oil in their recipe. Finally, although in our study the total content of the ketones exhibited the same general 
behaviours, 2,3-butanedione and acetoin showed opposite behaviours and it would be better to study them individually. Jensen et al. (2011a) reported the same pattern, with a decrease in the content of 2,3-butanedione in the first two weeks and an increase in the content of acetoin in the first week, although in their case acetoin decreased in the second week.

\subsubsection{Effectiveness of the freezing on the aroma preservation for analytical purposes}

When using the solvent extraction methodology, the average reduction in the content of the volatile compounds after one week of storage at room temperature was $39 \%$ while the average reduction after one week of freezing was $32 \%$, therefore supporting the efficacy of freezing for enhanced volatile compound retention. However, in the analysis of ethanol and ethyl acetate by SHS-GC/MS, the average loss at room temperature was $68 \%$ but the average loss during freezing was $20 \%$. As ethanol and ethyl acetate presented the lowest boiling points, the logical situation would be higher losses for them than for the volatile compounds of the solvent extraction methodology, as occurred with the sample stored at room temperature. This surprising high content of ethanol and ethyl acetate in the frozen samples is possibly related, somehow, with physicochemical changes. During the staling of bread, the amylose fraction retrogrades in the first hours of storage while the amylopectin fraction retrogrades over days, although staling has been reported to be mainly due to amylopectin retrogradation (Ronda, Caballero, Quilez \& Roos, 2011). The phenomenon of retrogradation implies that the amylose chains exuded from the starch grain are reoriented in parallel and interact with their hydroxyl groups through hydrogen bonds, while the amylopectin molecules are also associated through hydrogen bonds with their hydroxyl groups. This could lead to the hypothesis that the interaction of the volatile compounds with the hydroxyl groups of retrograded starch would be lower. Ronda et al. (2011) reported that the melting enthalpy of the amylopectin recrystallised in crumb after thawing was higher in the bread frozen for one 
week than in the fresh bread, which means that the frozen bread retrograded quicker. This would entail that the volatile compounds of the frozen bread would be released easier after thawing than in the fresh bread, due to the higher rate of retrogradation during freezing. As to our knowledge, the effect of retrogradation on the interaction between the starch and the volatile compounds during freezing has never been reported. In view of these results, we hypothesised that the explained effect of retrogradation during freezing should be negligible when using solvent extraction methodologies, probably due to the weakening of the hydrogen bonds in presence of the solvent. Thus, the selection of the suitable frozen storage time depends solely on the losses of volatile compounds. In order to avoid losses higher than $24 \%$, the bread samples should be analysed before one week of freezing for solvent extraction analyses. However, when using headspace methodologies the effect should be considered important due to the lack of intermolecular forces with a solvent, leading to an easier release of the volatile compounds from the matrix to the headspace with regard to the fresh bread. As the aim of freezing is to retain the volatile profile of the fresh bread until it is analysed, the easier release of the volatile compounds would disturb the aroma profile, leading to unreliable findings. This explains why the results between the solvent extraction method and SHS-GC/MS were incorrectly closer in the frozen bread than in the fresh one. Therefore, bread samples should be analysed on the same day as preparation if headspace analyses are made. By all means, if freezing is needed, temperatures under $28^{\circ} \mathrm{C}$ are suggested in order to decelerate the retrogradation of starch (Ronda \& Roos, 2011).

\section{Conclusions}

The impact of frozen storage time on the volatile profile of wheat bread crumb has been studied for the first time. It has been proven that frozen storage is able to maintain the 
aroma quality of the bread up to one week (average losses of 24\%), with losses of approximately $34 \%$ fewer of the volatile compounds regarding room temperature storage (average losses of 58\%). The profile of the frozen bread was characterised by losses lower than $20 \%$ of alcohols from fermentations such as 2/3-methyl-1-butanol, phenylethyl alcohol or benzyl alcohol and losses higher than $20 \%$ of volatile compounds from lipid oxidation like hexanal, 1-hexanol, 1-octen-3-ol, nonanal and 2(E)-nonenal. Moreover, after two weeks of freezing, there was an increase mainly in the content of acids and alcohols. Finally, after one month of freezing, 5 of the 38 volatile compounds were completely lost and the average losses increased up to 53\%. Regarding the analytical possibilities in light of these results, bread samples should be analysed before one week of frozen storage time by solvent extraction, in order to avoid losses of volatile compounds higher than $24 \%$. Concerning the static headspace methodology, the samples should be analysed on the same day as the bread is prepared, since the acceleration of the starch retrogradation during freezing could lead to higher releases of volatile compounds in the extraction than those expected in the fresh sample.

\section{Acknowledgements}

The authors acknowledge the financial support of the Spanish Ministry of Economy and Competitiveness (Project AGL2014-52928-C2-2-R) and the European Regional Development Fund (FEDER). Joana Pico would like to thank the University of Valladolid for her PhD fellowship. The authors would like to thank Anna Hayes for the revision of the English scientific language. 


\section{References}

Arvisenet, G., Le Bail, P., Voilley, A., \& Cayot, N. (2002). Influence of physicochemical interactions between amylose and aroma compounds on the retention of aroma in food-like matrices. Journal of Agricultural and Food Chemistry, 50(24), 7088-7093.

Bianchi, F., Careri, M., Chiavaro, E., Musci, M., \& Vittadini, E. (2008). Gas chromatographic-mass spectrometric characterisation of the Italian Protected Designation of Origin “Altamura” bread volatile profile. Food Chemistry, 110, 787-793.

Birch, A. N., Petersen, M. A., \& Hansen, A. S. (2013). The aroma profile of wheat bread crumb influenced by yeast concentration and fermentation temperature. $L W T$ - Food Science and Technology, 50, 480-488.

Birch, A. N., Petersen, M. A., \& Hansen, Å. S. (2014). Aroma of wheat bread crumb. Cereal Chemistry, 91(2), 105-114.

Capozzi, V., Makhoul, S., Aprea, E., Romano, A., Cappellin, L., Jimena, A. S., ... Biasioli, F. (2016). PTR-MS Characterization of VOCs Associated with Commercial Aromatic Bakery Yeasts of Wine and Beer Origin. Molecules, 21(4), $1-14$.

Chiavaro, E., Vittadini, E., Musci, M., Bianchi, F., \& Curti, E. (2008). Shelf-life stability of artisanally and industrially produced durum wheat sourdough bread (“Altamura bread”). LWT - Food Science and Technology, 41(1), 58-70.

Jensen, S., Oestdal, H., Skibsted, L. H., Larsen, E., \& Thybo, A. K. (2011a). Chemical changes in wheat pan bread during storage and how it affects the sensory perception of aroma, flavour, and taste. Journal of Cereal Science, 53(2), 259-268.

Jensen, S., Ostdal, H., Skibsted, L. H., \& Thybo, A. K. (2011b). Antioxidants and shelf life of whole wheat bread. Journal of Cereal Science, 53(3), 291-297. 
Latou, E., Mexis, S. F., Badeka, A. V., \& Kontominas, M. G. (2010). Shelf life extension of sliced wheat bread using either an ethanol emitter or an ethanol emitter combined with an oxygen absorber as alternatives to chemical preservatives. Journal of Cereal Science, 52(3), 457-465.

Le Bail, P., Biais, B., Pozo-Bayón, M. A., \& Cayot, N. (2004). The structure of complexes between amylose and aroma compounds and its impact on flavour release froma baked cereal product. In CIGR international conference Beijing. Bioproducts processing and food safety (oral comunication).

Le Thanh, M., Thibeaudeau, P., Thibaut, M. A., \& Voilley, A. (1992). Interactions between volatile and non-volatile compounds in the presence of water. Food Chemistry, 43(2), 129-135.

Luning, P. A., Roozen, J. P., Moëst, R. A. F. J., \& Posthumus, M. A. (1991). Volatile composition of white bread using enzyme active soya flour as improver. Food Chemistry, 41, 81-91.

Makhoul, S., Romano, A., Capozzi, V., Spano, G., Aprea, E., Cappellin, L., Benozzi, E., Scampiccio, M., M ärk, T.D., Gasperi, F., El-Nakat, H., \& Biasioli, F. (2015). Volatile Compound Production During the Bread-Making Process: Effect of Flour, Yeast and Their Interaction. Food and Bioprocess Technology, 8(9), 1925-1937.

Martínez-Anaya, M. A. (1996). Enzymes and Bread Flavor. Journal of Agricultural and Food Chemistry, 44(9), 2469-2479.

Paraskevopoulou, A., Chrysanthou, A., \& Koutidou, M. (2012). Characterisation of volatile compounds of lupin protein isolate-enriched wheat flour bread. Food Research International, 48(2), 568-577.

Pico, J., Nozal, M. J., Gómez, M., \& Bernal, J. L. (2016). An alternative method based on enzymatic fat hydrolysis to quantify volatile compounds in wheat bread crumb. Food Chemistry, 206, 110-118. 
Plessas, S., Alexopoulos, A., Bekatorou, A., Mantzourani, I., Koutinas, A. A., \& Bezirtzoglou, E. (2011). Examination of freshness degradation of sourdough bread made with kefir through monitoring the aroma volatile composition during storage. Food Chemistry, 124(2), 627-633.

Plessas, S., Bekatorou, A., Gallanagh, J., Nigam, P., Koutinas, A. A., \& Psarianos, C. (2008). Evolution of aroma volatiles during storage of sourdough breads made by mixed cultures of Kluyveromyces marxianus and Lactobacillus delbrueckii ssp. bulgaricus or Lactobacillus helveticus. Food Chemistry, 107, 883-889.

Poinot, P., Arvisenet, G., Grua-Priol, J., Fillonneau, C., Le-Bail, A., \& Prost, C. (2010). Influence of inulin on bread: Kinetics and physico-chemical indicators of the formation of volatile compounds during baking. Food Chemistry, 119(4), 14741484.

Rappenecker, G., \& Zugenmaier, P. (1981). Detailed refinement of the crystal structure of Vh amylose. Carbohydrate Research, 89(1), 11-19.

Ronda, F., Caballero, P. A., Quilez, J. \& Roos, Y. H. (2011). Staling of frozen partly and fully baked breads. Study of the combined effect of amylopectin recrystallization and water content on bread firmness. Journal of Cereal Science, $53,97-103$.

Ronda, F., \& Roos, Y. H. (2011). Staling of fresh and frozen gluten-free bread. Journal of Cereal Science, 53, $340-346$. 
Table 1. Peak area of the target ions $\left(\times 10^{6}\right)$ of the 38 volatile compounds studied in the crumb of the fresh bread and the bread stored for one week at $22^{\circ} \mathrm{C}$. Standard deviations (SD) are given after $\pm(n=4)$. Different letters in the same row indicate significant differences in Oneway Anova (95\% significance level).

\begin{tabular}{|c|c|c|c|c|}
\hline Volatile compounds & Fresh & 1 week & $\%_{\text {losses }^{b}}$ & p-value \\
\hline Ethanol $^{\mathrm{a}}$ & $39.332 b \pm 4.720$ & $11.651 \mathrm{a} \pm 1.305$ & 70 & 0.0026 \\
\hline Ethyl acetate $^{a}$ & $6.345 b \pm 0.318$ & $2.243 \mathrm{a} \pm 0.067$ & 65 & 0.0012 \\
\hline 2,3-Butanedione & $3.354 a \pm 0.323$ & $2.320 a \pm 0.157$ & 31 & 0.0553 \\
\hline 1-Propanol & $1.179 b \pm 0.065$ & $0.516 a \pm 0.021$ & 56 & 0.0053 \\
\hline 2-Methyl-1-propanol & $6.715 b \pm 0.102$ & $0.882 a \pm 0.020$ & 87 & 0.0002 \\
\hline Hexanal & $12.671 b \pm 0.129$ & $7.705 a \pm 0.032$ & 39 & 0.0004 \\
\hline 3-Penten-2-ol & $4.069 \mathrm{~b} \pm 0.103$ & $3.140 \mathrm{a} \pm 0.028$ & 23 & 0.0066 \\
\hline 2-Methyl-1-butanol & $4.942 b \pm 0.032$ & $1.841 \mathrm{a} \pm 0.011$ & 63 & 0.0001 \\
\hline 3-Methyl-1-butanol & $9.970 b \pm 0.095$ & $3.983 a \pm 0.056$ & 60 & 0.0002 \\
\hline 1-Pentanol & $1.224 \mathrm{a} \pm 0.019$ & $1.186 \mathrm{a} \pm 0.014$ & 3 & 0.1502 \\
\hline Acetoin & $7.808 \mathrm{a} \pm 0.183$ & $12.309 b \pm 0.268$ & -58 & 0.0026 \\
\hline R-(+)-Limonene & $0.019 b \pm 0.002$ & $0.0085 a \pm 0.0004$ & 55 & 0.0114 \\
\hline 2-Octanone & $0.348 \mathrm{~b} \pm 0.017$ & $0.193 \mathrm{a} \pm 0.001$ & 44 & 0.0058 \\
\hline 1-Hexanol & $2.539 b \pm 0.034$ & $1.646 \mathrm{a} \pm 0.018$ & 35 & 0.0009 \\
\hline Acetic acid & $403.680 b \pm 1.859$ & $344.030 \mathrm{a} \pm 5.336$ & 15 & 0.0045 \\
\hline Furfural & $1.817 \mathrm{~b} \pm 0.025$ & $0.470 \mathrm{a} \pm 0.004$ & 74 & 0.0002 \\
\hline Methional & $0.0066 b \pm 0.0003$ & $0.0046 a \pm 0.0002$ & 31 & 0.0198 \\
\hline 1-Octen-3-ol & $0.196 \mathrm{~b} \pm 0.002$ & $0.113 a \pm 0.006$ & 42 & 0.0031 \\
\hline Nonanal & $0.863 b \pm 0.007$ & $0.604 \mathrm{a} \pm 0.025$ & 30 & 0.0050 \\
\hline 2,3-butanediol & $203.014 b \pm 4.621$ & $162.075 a \pm 7.192$ & 20 & 0.0211 \\
\hline 2-Ethyl-1-hexanol & $0.444 b \pm 0.003$ & $0.030 \mathrm{a} \pm 0.001$ & 93 & 0.0000 \\
\hline Isobutyric acid & $20.648 b \pm 0.139$ & $15.903 \mathrm{a} \pm 0.743$ & 23 & 0.0125 \\
\hline Benzaldehyde & $0.136 b \pm 0.004$ & $0.094 \mathrm{a} \pm 0.002$ & 31 & 0.0057 \\
\hline 1,2-Propanediol & $12.571 b \pm 0.194$ & $10.569 \mathrm{a} \pm 0.491$ & 16 & 0.0331 \\
\hline Ethyl octanoate & $0.259 b \pm 0.008$ & $0.132 \mathrm{a} \pm 0.001$ & 49 & 0.0021 \\
\hline 5-Methyl-2-furaldehyde & $1.041 \mathrm{~b} \pm 0.011$ & $0.133 a \pm 0.003$ & 87 & 0.0001 \\
\hline Butyric acid & $4.651 b \pm 0.022$ & $3.596 a \pm 0.183$ & 23 & 0.0149 \\
\hline Butyrolactone & $1.177 \mathrm{~b} \pm 0.025$ & $0.825 \mathrm{a} \pm 0.015$ & 30 & 0.0034 \\
\hline 2-(E)-Nonenal & $1.751 \mathrm{~b} \pm 0.006$ & $1.395 \mathrm{a} \pm 0.080$ & 20 & 0.0244 \\
\hline 3-Methylbutanoic acid & $5.054 b \pm 0.007$ & $3.960 \mathrm{a} \pm 0.121$ & 22 & 0.0061 \\
\hline 2-Methylbutanoic acid & $1.568 \mathrm{~b} \pm 0.002$ & $1.156 \mathrm{a} \pm 0.044$ & 26 & 0.0058 \\
\hline Phenylacetaldehyde & $0.059 \mathrm{~b} \pm 0.000$ & $0.022 \mathrm{a} \pm 0.002$ & 62 & 0.0014 \\
\hline 1,3-Butanediol & $0.848 \mathrm{a} \pm 0.020$ & $0.733 \mathrm{a} \pm 0.072$ & 14 & 0.1627 \\
\hline Hexanoic acid & $18.920 \mathrm{~b} \pm 0.019$ & $14.855 a \pm 0.777$ & 21 & 0.0178 \\
\hline Benzyl alcohol & $1.782 b \pm 0.041$ & $1.494 \mathrm{a} \pm 0.039$ & 16 & 0.0186 \\
\hline Phenylethyl alcohol & $13.132 b \pm 0.303$ & $11.589 \mathrm{a} \pm 0.111$ & 12 & 0.0212 \\
\hline 2,4-(E,E)-Decadienal & $0.206 b \pm 0.001$ & $0.056 a \pm 0.003$ & 73 & 0.0002 \\
\hline 4-Vinylguaiacol & $7.876 b \pm 0.048$ & $5.965 \mathrm{a} \pm 0.154$ & 24 & 0.0036 \\
\hline
\end{tabular}

${ }^{a}$ Ethyl alcohol and ethyl acetate were analysed by SHS-GC/MS. The other 36 volatile compounds were analysed by solvent extraction and GC/MS.

${ }^{b} \%$ losses calculated compared to the fresh sample. Negative values imply that the peak area of the target ion increased compared to the fresh crumb. 
Table 2. Peak area of the target ions $\left(x 10^{6}\right)$ of the 38 volatile compounds studied in the crumb of the fresh bread and the bread frozen for one, two and four weeks at $-21^{\circ} \mathrm{C}$. Standard deviations (SD) are given after $\pm(n=4)$. Different letters in the same row indicate significant differences in One-way Anova $(95 \%$ significance level).

\begin{tabular}{|c|c|c|c|c|c|c|c|c|}
\hline Volatile compounds & Fresh & 1 week & $\begin{array}{c}\% \\
\text { losses }^{b}\end{array}$ & 2 weeks & $\begin{array}{c}\% \\
\text { losses }^{b}\end{array}$ & 4 weeks & $\begin{array}{c}\% \\
\text { losses }^{b}\end{array}$ & p-value \\
\hline Ethyl acetate $^{\text {a }}$ & $6.345 c \pm 0.189$ & $5.000 a \pm 0.186$ & 21 & $5.220 a b \pm 0.175$ & 18 & $5.415 b \pm 0.143$ & 15 & 0.0035 \\
\hline Ethanol $^{a}$ & $39.332 b \pm 3.456$ & $32.000 \mathrm{a} \pm 3.001$ & 19 & $44.614 c \pm 4.065$ & -13 & $41.821 b c \pm 4.013$ & -6 & 0.0025 \\
\hline 2,3-Butanedione & $3.354 c \pm 0.323$ & $1.606 \mathrm{~b} \pm 0.024$ & 52 & $0.953 a \pm 0.010$ & 72 & $\mathrm{nd}^{\mathrm{c}}$ & 100 & 0.0001 \\
\hline 1-Propanol & $1.179 a \pm 0.065$ & $1.381 \mathrm{a} \pm 0.018$ & -17 & $1.415 \mathrm{a} \pm 0.058$ & -20 & $1.425 \mathrm{a} \pm 0.130$ & -21 & 0.0960 \\
\hline 2-Methyl-1-propanol & $6.715 c \pm 0.102$ & $6.187 b \pm 0.056$ & 8 & $6.788 c \pm 0.010$ & -1 & $4.284 a \pm 0.034$ & 36 & 0.0000 \\
\hline Hexanal & $12.671 d \pm 0.129$ & $9.938 c \pm 0.051$ & 22 & $9.019 b \pm 0.188$ & 29 & $4.526 a \pm 0.209$ & 64 & 0.0000 \\
\hline 3-Penten-2-ol & $4.069 c \pm 0.103$ & $3.526 b \pm 0.047$ & 13 & $3.952 c \pm 0.102$ & 3 & $0.056 a \pm 0.001$ & 99 & 0.0000 \\
\hline 2-Methyl-1-butanol & $4.942 c \pm 0.032$ & $4.507 b \pm 0.018$ & 9 & $4.859 c \pm 0.003$ & 2 & $3.130 \mathrm{a} \pm 0.183$ & 37 & 0.0001 \\
\hline 3-Methyl-1-butanol & $9.970 \mathrm{c} \pm 0.095$ & $8.998 b \pm 0.058$ & 10 & $8.951 b \pm 0.036$ & 10 & $5.774 a \pm 0.009$ & 42 & 0.0000 \\
\hline 1-Pentanol & $1.224 d \pm 0.019$ & $1.060 c \pm 0.015$ & 13 & $0.586 b \pm 0.009$ & 52 & $0.314 a \pm 0.010$ & 74 & 0.0000 \\
\hline Acetoin & $7.808 a \pm 0.183$ & $9.435 b \pm 0.064$ & -21 & $12.868 c \pm 0.161$ & -65 & $7.226 a \pm 0.379$ & 7 & 0.0001 \\
\hline $\mathrm{R}-(+)$-Limonene & $0.019 c \pm 0.002$ & $0.008 b \pm 0.001$ & 55 & $0.0017 a \pm 0.0001$ & 91 & $\mathrm{nd}^{\mathrm{c}}$ & 100 & 0.0001 \\
\hline 2-Octanone & $0.348 c \pm 0.017$ & $0.2363 b \pm 0.0003$ & 32 & $0.251 b \pm 0.005$ & 28 & $0.130 \mathrm{a} \pm 0.002$ & 63 & 0.0001 \\
\hline 1-Hexanol & $2.539 c \pm 0.034$ & $1.912 b \pm 0.035$ & 25 & $2.034 b \pm 0.083$ & 20 & $0.597 a \pm 0.006$ & 76 & 0.0000 \\
\hline Acetic acid & $403.680 \mathrm{~d} \pm 1.859$ & 301.126 c \pm 3.202 & 25 & $319.549 \mathrm{~b} \pm 9.703$ & 21 & $177.242 \mathrm{a} \pm 2.381$ & 56 & 0.0000 \\
\hline Furfural & $1.817 d \pm 0.025$ & $0.926 c \pm 0.005$ & 49 & $0.755 b \pm 0.001$ & 58 & $0.426 a \pm 0.007$ & 77 & 0.0000 \\
\hline Methional & $0.0066 \mathrm{~d} \pm 0.0003$ & $0.0042 c \pm 0.0002$ & 37 & $0.0026 b \pm 0.0001$ & 61 & $0.00118 a \pm 0.00003$ & 82 & 0.0001 \\
\hline 1-Octen-3-ol & $0.196 c \pm 0.002$ & $0.127 b \pm 0.002$ & 35 & $0.131 b \pm 0.011$ & 33 & $0.073 a \pm 0.006$ & 63 & 0.0002 \\
\hline Nonanal & $0.863 d \pm 0.007$ & $0.504 c \pm 0.006$ & 42 & $0.294 b \pm 0.007$ & 66 & $0.112 a \pm 0.004$ & 87 & 0.0000 \\
\hline 2,3-butanediol & 203.014 c \pm 4.621 & $150.509 b \pm 1.506$ & 26 & $208.044 c \pm 0.271$ & -2 & $113.890 a \pm 3.010$ & 44 & 0.0000 \\
\hline
\end{tabular}

${ }^{a}$ Ethyl alcohol and ethyl acetate were analysed by SHS-GC/MS. The other 36 volatile compounds were analysed by solvent extraction and GC/MS.

${ }^{b} \%$ losses calculated compared to the fresh sample. Negative values imply that the peak area of the target ion increased compared to the fresh crumb.

${ }^{c}$ nd $=$ not detected. 
Table 2. (continued).

\begin{tabular}{|c|c|c|c|c|c|c|c|c|}
\hline Volatile compounds & Fresh & 1 week & $\%$ losses $^{b}$ & 2 weeks & $\begin{array}{c}\% \\
\text { losses b }\end{array}$ & 4 weeks & $\begin{array}{c}\% \\
\text { losses }\end{array}$ & p-value \\
\hline 2-Ethyl-1-hexanol & $0.444 b \pm 0.003$ & $0.025 a \pm 0.006$ & 94 & $\mathrm{nd}^{\mathrm{c}}$ & 100 & $\mathrm{nd}^{\mathrm{c}}$ & 100 & 0.0000 \\
\hline Isobutyric acid & $20.648 d \pm 0.139$ & $13.145 \mathrm{~b} \pm 0.316$ & 36 & $14.232 \mathrm{c} \pm 0.551$ & 31 & $7.769 \mathrm{a} \pm 0.410$ & 62 & 0.0000 \\
\hline Benzaldehyde & $0.136 d \pm 0.004$ & $0.119 c \pm 0.004$ & 12 & $0.105 b \pm 0.001$ & 23 & $0.079 \mathrm{a} \pm 0.004$ & 42 & 0.0004 \\
\hline 1,2-Propanediol & $12.571 \mathrm{~d} \pm 0.194$ & $8.196 c \pm 0.099$ & 35 & $6.226 \mathrm{~b} \pm 0.322$ & 50 & $3.649 \mathrm{a} \pm 0.025$ & 71 & 0.0000 \\
\hline Ethyl octanoate & $0.259 b \pm 0.008$ & $0.131 \mathrm{a} \pm 0.006$ & 49 & $n d^{c}$ & 100 & $\mathrm{nd}^{\mathrm{c}}$ & 100 & 0.0000 \\
\hline 5-Methyl-2-furaldehyde & $1.041 d \pm 0.011$ & $0.3741 c \pm 0.004$ & 64 & $0.3018 b \pm 0.0002$ & 71 & $0.155 a \pm 0.003$ & 85 & 0.0000 \\
\hline Butyric acid & $4.651 b \pm 0.022$ & $3.271 \mathrm{a} \pm 0.028$ & 30 & $5.314 c \pm 0.299$ & -14 & $3.197 \mathrm{a} \pm 0.107$ & 31 & 0.0004 \\
\hline Butyrolactone & $1.177 \mathrm{~d} \pm 0.025$ & $0.801 c \pm 0.011$ & 32 & $0.624 \mathrm{~b} \pm 0.008$ & 47 & $0.348 \mathrm{a} \pm 0.014$ & 70 & 0.0000 \\
\hline 2-(E)-Nonenal & $1.751 \mathrm{~d} \pm 0.006$ & $1.111 c \pm 0.002$ & 37 & $0.847 \mathrm{~b} \pm 0.019$ & 52 & $0.402 \mathrm{a} \pm 0.008$ & 77 & 0.0000 \\
\hline 3-Methylbutanoic acid & $5.054 c \pm 0.007$ & $3.664 \mathrm{a} \pm 0.011$ & 28 & $5.949 d \pm 0.046$ & -18 & $3.775 b \pm 0.058$ & 25 & 0.0000 \\
\hline 2-Methylbutanoic acid & $1.568 b \pm 0.002$ & $1.041 \mathrm{a} \pm 0.008$ & 34 & $1.586 \mathrm{~b} \pm 0.049$ & -1 & $1.041 \mathrm{a} \pm 0.037$ & 34 & 0.0001 \\
\hline Phenylacetaldehyde & $0.05909 \mathrm{c} \pm 0.00002$ & $0.021 b \pm 0.001$ & 65 & $0.0113 \mathrm{a} \pm 0.0002$ & 81 & $\mathrm{nd}^{\mathrm{c}}$ & 100 & 0.0000 \\
\hline 1,3-Butanediol & $0.848 d \pm 0.020$ & $0.719 c \pm 0.022$ & 15 & $0.600 \mathrm{~b} \pm 0.033$ & 29 & $0.211 \mathrm{a} \pm 0.001$ & 75 & 0.0000 \\
\hline Hexanoic acid & $18.920 \mathrm{~b} \pm 0.019$ & $14.661 \mathrm{a} \pm 0.173$ & 23 & $14.717 \mathrm{a} \pm 0.250$ & 22 & $14.277 \mathrm{a} \pm 0.211$ & 25 & 0.0000 \\
\hline Benzyl alcohol & $1.782 b \pm 0.041$ & $1.418 \mathrm{a} \pm 0.027$ & 20 & $2.404 c \pm 0.089$ & -35 & $1.438 \mathrm{a} \pm 0.015$ & 19 & 0.0001 \\
\hline Phenylethyl alcohol & $13.132 b \pm 0.303$ & $11.280 \mathrm{a} \pm 0.101$ & 14 & $20.252 d \pm 0.140$ & -54 & $17.401 c \pm 0.348$ & -33 & 0.0000 \\
\hline 2,4-(E,E)-Decadienal & $0.206 a \pm 0.001$ & $0.255 b \pm 0.009$ & -24 & $0.263 b \pm 0.010$ & -28 & $0.204 a \pm 0.001$ & 1 & 0.0017 \\
\hline 4-Vinylguaiacol & $7.876 a \pm 0.048$ & $6.301 a \pm 0.039$ & 20 & $6.528 a \pm 0.040$ & 17 & $6.395 a \pm 0.345$ & 19 & 0.1598 \\
\hline
\end{tabular}

${ }^{b} \%$ losses calculated compared to the fresh sample. Negative values imply that the peak area of the target ion increased compared to the fresh crumb.

${ }^{c}$ nd $=$ not detected. 
Table S1. Volatile compounds studied in the fresh sample, the sample stored for one week at $22^{\circ} \mathrm{C}$ as well as the samples frozen for one, two and four weeks, in order of elution (Rt, retention time). Target $(\mathrm{T})$ and qualifier $(\mathrm{Q} 1, \mathrm{Q} 2,+\mathrm{Q})$ ions employed for each compound are given in the table.

\begin{tabular}{|c|c|c|c|c|c|}
\hline Volatile compounds & $\mathbf{R t}$ & $T$ & Q1 & Q2 & $Q+$ \\
\hline Ethanol $^{\mathrm{a}}$ & 5.824 & 31 & 45 & 46 & 29 \\
\hline Ethyl acetate $^{\text {a }}$ & 5.831 & 43 & 61 & 70 & 29 \\
\hline 2,3-Butanedione & 6.647 & 43 & 31 & 86 & 15 \\
\hline 1-Propanol & 7.267 & 31 & 42 & 59 & 60 \\
\hline 2-Methyl-1-propanol & 8.432 & 43 & 41 & 74 & 55 \\
\hline Hexanal & 9.623 & 56 & 44 & 72 & 82 \\
\hline 3-Penten-2-ol & 9.909 & 71 & 43 & 53 & 86 \\
\hline 2-Methyl-1-butanol & 10.883 & 55 & 70 & 41 & 57 \\
\hline 3-Methyl-1-butanol & 10.919 & 57 & 41 & 70 & 29 \\
\hline 1-Pentanol & 12.115 & 42 & 55 & 70 & 91 \\
\hline Acetoin & 12.081 & 45 & 88 & 27 & 15 \\
\hline R-(+)-Limonene & 14.920 & 68 & 93 & 79 & 107 \\
\hline 2-Octanone & 14.922 & 58 & 71 & 85 & 128 \\
\hline 1-Hexanol & 14.870 & 56 & 41 & 42 & 55 \\
\hline Acetic acid & 14.474 & 45 & 60 & 15 & 29 \\
\hline Furfural & 17.594 & 96 & 39 & 29 & 67 \\
\hline Methional & 18.182 & 48 & 104 & 76 & 61 \\
\hline 1-Octen-3-ol & 18.994 & 57 & 72 & 43 & 85 \\
\hline Nonanal & 19.769 & 57 & 41 & 70 & 98 \\
\hline 2,3-butanediol & 20.642 & 45 & 57 & 29 & 75 \\
\hline 2-Ethyl-1-hexanol & 21.159 & 57 & 41 & 70 & 83 \\
\hline Isobutyric acid & 21.446 & 43 & 41 & 73 & 27 \\
\hline Benzaldehyde & 21.907 & 106 & 105 & 77 & 51 \\
\hline 1,2-Propanediol & 22.528 & 45 & 43 & 61 & 29 \\
\hline Ethyl octanoate & 22.823 & 88 & 101 & 127 & 57 \\
\hline 5-Methyl-2-furaldehyde & 23.579 & 110 & 109 & 53 & 81 \\
\hline Butyric acid & 24.854 & 60 & 73 & 42 & 27 \\
\hline Butyrolactone & 25.533 & 42 & 28 & 86 & 56 \\
\hline 2-(E)-Nonenal & 26.491 & 70 & 55 & 41 & 83 \\
\hline 3-Methylbutanoic acid & 27.929 & 60 & 43 & 87 & 39 \\
\hline 2-Methylbutanoic acid & 27.985 & 57 & 74 & 87 & 41 \\
\hline Phenylacetaldehyde & 28.320 & 91 & 120 & 92 & 65 \\
\hline 1,3-Butanediol & 32.366 & 43 & 45 & 57 & 72 \\
\hline Hexanoic acid & 40.674 & 60 & 73 & 87 & 41 \\
\hline Benzyl alcohol & 41.605 & 79 & 108 & 91 & 51 \\
\hline Phenylethyl alcohol & 42.424 & 91 & 122 & 65 & 77 \\
\hline 2,4-(E,E)-Decadienal & 43.101 & 81 & 67 & 95 & 152 \\
\hline 4-Vinylguaiacol & 45.617 & 150 & 135 & 107 & 77 \\
\hline
\end{tabular}

a Ethyl alcohol and ethyl acetate were analysed by SHS-GC/MS. The other 36 volatile compounds were analysed by solvent extraction and GC/MS. 


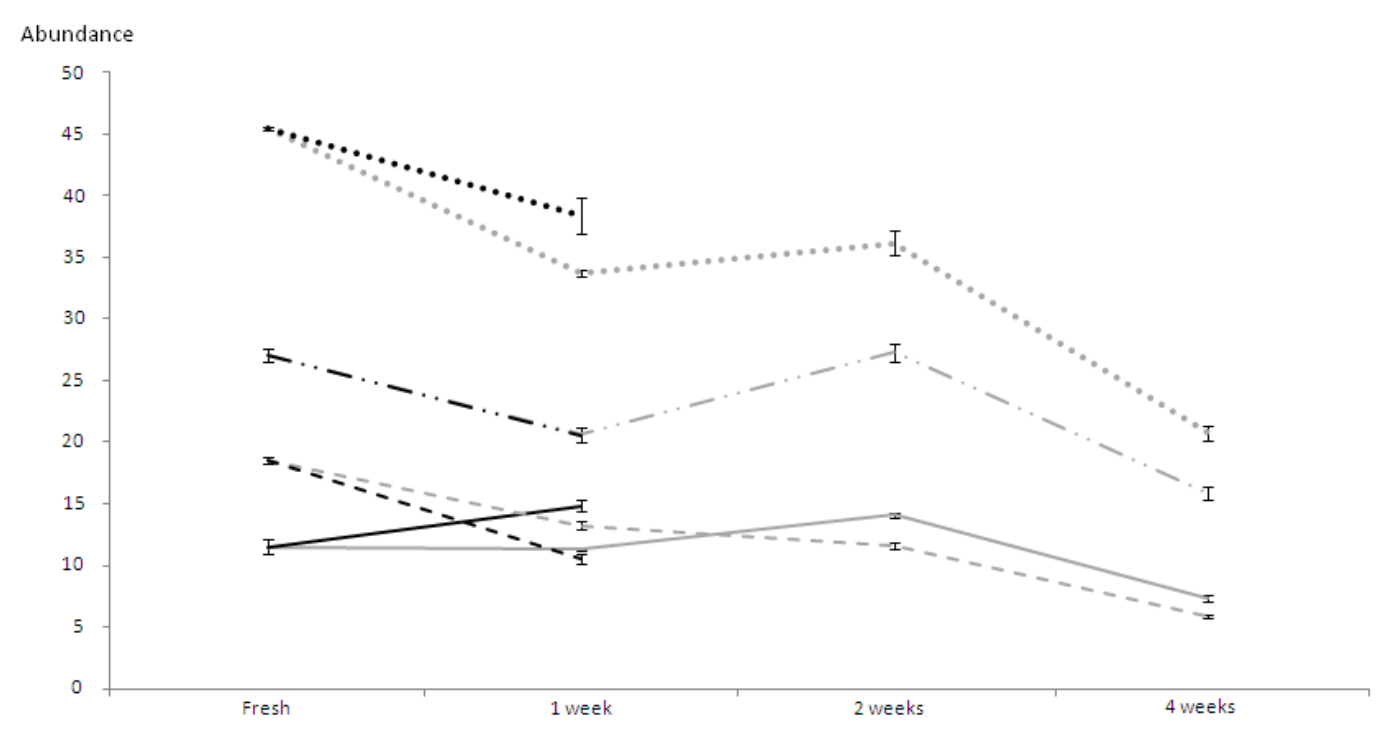

Fig. 1. Evolution of the main groups of volatile compounds in the wheat crumb stored for one week at room temperature (black lines) and in the wheat crumb frozen for one, two and four weeks (grey lines). The results are the sum of the peak areas of the ketones (continuous line, $\times 10^{6}$ ), aldehydes (discontinuous line, $\times 10^{6}$ ), alcohols (scratch-doubly spotted line, $\times 10^{7}$ ) and acids (spotted line, $\times 10^{7}$ ). 